\title{
LOS CAMINOS DE LA HISTORIA. DEL GUSTO A LA ERUDICIÓN
}

BENJAMIN FLORES HERNANNDEZ

Departamento de Historia/UAA

XAVIER GONZÁLEZ FISHER, Tocados por los duendes. Diez figuras en la edad de plata del toreo en México, Aguascalientes, CIEMA/ Instituto Cultural de Aguascalientes, 2000, $156 \mathrm{pp}$.

La de que todo es historia o, cuando menos, todo puede ser historia, resulta una convicción que día a día se afianza en nuestra conciencia, referida a la inagotable diversidad temática y a la enorme variedad de técnicas, marcos teóricos, enfoques metodológicos, fuentes de información y formas de comunicación de resultados con los que nuestra actualidad historiográfica realiza su tarea de acercamiento al pasado humano para descubrirlo, explicarlo, interpretarlo: conocerlo en fin, de una u otra manera. Estamos en la pretensión de que, sabiendo cómo y qué fueron los hombres y las mujeres de otras épocas y de otros lugares - con los que nos hermana, por lo pronto, esa nuestra compartida humanidad, si no es que también una cierta relación de continuidad biológica, cultural o meramente espacial- estaremos avanzando en la construcción de un saber fundamental para cumplir la empresa de nuestra vida: qué y cómo somos nosotros, hic et nunc, ahora, en este lugar, en este tiempo.

El interés acerca del pasado surge en el presente, de la propia situación en la que se está; para entender ésta, para explicarla, para tener más cabales armas para actuar sobre ella es que nos sentimos precisados a acudir a los que comprendemos sus orígenes. Antes que nada, la historia que nos interesa es precisamente la de lo que es importante para nosotros, 
la de aquello que efectivamente nos significa algo, la que tiene que ver con lo que de verdad somos y con lo que queremos seguir siendo hacia el futuro. La función del saber histórico es la de plantearnos paradigmas para precisar nuestra ubicación en el mundo en el que nos tocó vivir, para confirmar o replantear su sentido, al vincularlo con el pensar, el sentir y el actuar de los que entendemos como nuestros predecesores.

Es a partir de tales consideraciones que habremos de pensar, para valorarlo en su exacta significación, el sitio que puede ocupar dentro de la historiografía un libro como el que vamos a comentar, que quiere dar cuenta de lo ocurrido en nuestro país, hace cuarenta o cincuenta años, con aquella que, en nuestra experiencia cultural de mexiçanos, todavía se nos representa como una de las ocasiones de regocijo y festividad más entrañablemente compartidas por muchos de los connacionales.

El punto de arranque para este tipo trabajos de recordación de lo que fueron en el pretérito nuestras diversiones de hoy es el pretender rescatar para la memoria colectiva lo que se entiende como antecedente imprescindible de algo que en el presente, en la actualidad personal y grupal, se vive, antes que nada, como un gusto, como la libre coparticipación en el disfrute de un festejo a través del cual nuestras existencias reafirman su sentido al abocarse a analizar algo importante de puro cotidiano, al ser querida forma de buscar la trascendencia a partir de lo en apariencia irrelevante.

Para los mexicanos, desde el momento preciso del surgimiento de lo que luego habría de aparecérsenos como una nacionalidad, hace ya casi medio milenio, tras la culminación de la Conquista y con las primeras actividades de colonización y de asentamiento en la tierra de peninsulares recién arribados, indígenas en trance de problemática asimilación y mestizos apenas por empezar a nacer, la de las corridas de toros ha sido una experiencia continua, compartida en un principio a través de todo el ámbito de lo que fuera la monarquía española y, luego del proceso de desintegración de ésta en el siglo XIX, restringida a sólo algunas regiones del extensísimo territorio que abarcara ella en su momento de máxima expansión: buena parte, aunque no toda la península ibérica -Portugal, España sin Galicia y ciertas zonas del sur de Francia-y, en el continente ameri- 
cano, amplias comarcas de los actuales países de México, Colombia, Venezuela, Ecuador y Perú, a más de una escasa supervivencia en Centroamérica.

Si para un número significativo de los naturales de los países mencionados la asistencia y el disfrute en la diversión taurina, en su forma contemporánea, representa parte importante de su entorno vital, la de los que a sí mismos se llaman cabales aficionados es una comunidad acotada, que se presenta ante sí misma como un grupo de iniciados en los secretos ciertos pero misteriosos implicados por el completo y auténtico disfrute de la función y de sus entretelones. Es entonces que surgen, alrededor de la fiesta brava, como se conoce al espectáculo montado hoy en día en torno al sacrificio de machos bovinos en un recinto construido ex profeso, grupos de personas que pretenden prolongar su fruición de ella para antes y para después de la celebración de la corrida. Tales son, entre otros, los llamados círculos o peñas taurinas, en el seno de una de las cuales, establecida hace ya catorce años en la ciudad de Aguascalientes, el Centro Taurino México y España, es que se produjo la composición del texto que motiva estas reflexiones. Y ello, en un contexto general en el que el desinterés y el aburrimiento de amplios sectores de la población, la masificación de las alternativas de convivencia, las corruptelas dentro del negocio y la proliferación de nuevas maneras de emplear el tiempo libre hacen que cada vez resulte la de los festejos taurinos una opción de diversión de menor relevancia dentro de nuestras sociedades. ${ }^{1}$

Lo mismo que en otras muchas asociaciones de la misma o parecida índole que operan en numerosas poblaciones de nuestros países hispánicos, e incluso en otras naciones como Francia o los Estados Unidos, las hebdomadarias sesiones que tienen los socios del Centro, aparte de comentar la actualidad del mundillo del toro, las dedican a lo que

1 Situación esta que, de todos modos, habría que analizar con cuidado, pues frente a signos de disminución en el interés taurómaco se están dando también otros que parecen apuntar en la dirección opuesta, tales algunos que, en la última década, se están haciendo bastante notorios en España, donde la europeización y la globalización no han disminuido el número de corridas celebradas año con año ni el de los asistentes a las plazas, de ningún modo sólo colmadas de turistas extranjeros. 
llaman, precisamente, "recuerdos y remembranzas", es decir a traer a la memoria, para compartirlos entre sí, anécdotas, sucedidos y procesos del pasado, en el no olvido de los cuales encuentra consistencia y autenticidad su participación comunitaria de conocedores de verdad.

Porque en esa complicidad de gente que chanela y que se acuerda de momentos que a la distancia de los años se han convertido en legendarios y sustentadores de una continuidad en el culto de lo taurómaco es que encuentra buena parte de su realidad la perennidad de saberse partícipes de un conocimiento valioso, sólo compartido por el grupo. Y más si quien los trae a la plática no sólo sabe de ellos por referencia, sino nada menos que por haber estado allí cuando se produjeron. Esa era la emoción, por ejemplo, de aquel "hombre del casino provinciano/ que vio a Cara ancha recibir un día", que recuerda Antonio Machado en sus célebres versos, quizás sin acabarlo de entender generosamente el hermano de aquel otro escritor que, según confesión propia, hubiera preferido ser "en vez de un tal poeta/ un buen banderillero".

En fin, lo que trato de traer a la consideración de los lectores de Caleidoscopio ahora es cómo, a partir del placer que en la contemplación apasionada e incluso partidista del que acude a una plaza de toros para aplaudir, protestar, emocionarse, divertirse, sufrir, gozar, manifestarse, entender o simplemente mirar con interés la labor de un profesional delante de una res brava, y en el deseo de convocar ante su imaginación cada vez que se le antoje lo que sucedió en aquella ocasión -in illo tempore, como en cualquier mito que se respeta-puede producirse y de hecho se está desarrollando todo un interesante género historiográfico que, con todo derecho, pretende sentar sus reales, cada vez con mayor rigor metodológico, ante la comunidad de los intelectuales y los historiadores.

En el ejercicio de esta especial categoría literaria, Xavier González Fisher, viejo aficionado que apenas inicia el quinto decenio de sus años, catedrático universitario, abogado litigante y aguascalentense de avanzada, en la actualidad en su tercer bienio de presidente del Centro, ha elegido en esta ocasión por tema para sus indagaciones del ayer torero una etapa a la que, por diferenciarla de la ya clásicamente 
entendida como dorada, inmediatamente anterior, ha decidido llamar de plata, sin que ello implique a priori un estatus inferior ni mucho menos. ${ }^{2}$ A la empresa se dedicó con entusiasmo, y la fue cumpliendo en diez diferentes sesiones del mencionado grupo, en cuyo turno de disertación se fue refiriendo sucesivamente a diez de los matadores mexicanos más importantes de ese periodo. Un periodo que en la actualidad es cierto que se aparece como disminuido entre el esplendor del inmediato previo -la legendaria época de los treintas y los cuarentas, enseñoreada por las legendarias figuras de Fermín Espinoza, Armillita, y Lorenzo Garza, El Soldado, o Silverio Pérez- y ese otro tiempo que para los de mi generación resulta el de nuestra añorada juventud, cuando en los quince años que van de 1967 a 1982 las plazas se llenaban y las ovaciones se desgranaban al conjuro de las

2 Hace unos cuantas semanas se presentó en la Facultad de Filosofía y Letras de la Universidad Nacional Autónoma de México la tesis de licenciatura en Historia de Luis Balderas Calderón intitulada Una "época dorada". La fiesta de toros en los años cuarenta en México, que dirigí. hazañas de Currito Rivera, Eloy Cavazos, Mariano Ramos y, paradigmáticamente, Manolo Martínez.

Tal el asunto de este volumen pulcramente publicado por el Centro de Investigaciones y Estudios Multidisciplinarios de Aguascalientes y el Instituto Cultural de Aguascalientes, de incuestionable garra y atractivo en especial para los que ya rebasamos los treinta años de ver toros, para quienes los nombres evocados allí -los de los matadores elegidos, claro, pero también los de los peones, los ganaderos, los empresarios, los cronistas, las figuras públicas o los meros representantes de la gente del toro que por allí desfilan-no son sólo dato importante para una historia de la que nos sentimos parte sino nostalgia pura, en el mejor y más entrañable sentido de la palabra.

Recordar la valentía y decisión de Antonio Velázquez, la desbordada pasión de Rafael Rodríguez, la serenidad y el buen hacer de Juanito Silveti, la sapiencia de Chucho Córdoba, la inconmensurabilidad de Capetillo, el temple que Humberto Moro atesoraba en la mano izquierda, la expresividad del Ranchero Aguilar, la aristocrática elegancia de Alfredo 
Leal, la hombría de Joselito Huerta o el misterioso silencio del Callao representa, para algunos de nosotros -para mí, lo digo sin rubor en singular- remitirme a una época entrañable, cuando los ciudadanos de este país confiábamos sin reticencias en un "desarrollo estabilizador" que incluso creímos "milagro mexicano", cuando los Adolfos eran presidentes de la República, el dólar costaba doce cincuenta, oíamos misa en latín, el Guadalajara le ganaba al América de todas todas en el partido decisivo de la liga, sufríamos con las primeras novelas de la televisión o veíamos los domingos el Teatro fantástico de Cachirulo, en la radio escuchábamos roncanroles, chachachás y las rancheras de José Alfredo Jiménez y en el cine disfrutábamos por cuatro pesos, cuando mucho, las películas en technicolor y cinemascope protagonizadas por Marilyn Monroe, Gina Lollobrigida, Sarita Montiel, Silvia Pinal o Viruta y Capulina.

González Fisher confiesa que personalmente él sólo presenció la actuación de dos o tres de sus biografiados, mas en verdad que la imagen torera que de ellos presenta resulta no sólo convincente sino, hasta donde nos llega la memoria, exacta. Para conseguir eso, llevó a cabo una tarea de localización de fuentes, de utilización de testimonios y de interpretación de textos que viene a ser uno de sus mejores aciertos. Es entonces que se muestra como verdadero historiador, de acuerdo con las más estrictas reglas del oficio. Para conocer, hoy, cómo fue la realidad taurina de hace cuatro o cinco décadas, acude con conocimiento de causa a los periódicos, a las entrevistas, a las fotografías, a las filmaciones, y localiza a sus informantes donde se encuentran. Y lo hace con apreciable intuición, llegando hasta los mejores de tales testimonios con los que podría haberse topado. Así, pongo por casos reveladores, los video-tapes de aquellas corridas de principios de los sesenta transmitidas con la cátedra de Pepe Alameda, o las "Cartas boca arriba" que Carlos León publicaba en Novedades los lunes de temporada grande en la México: allí están, limpiamente transcritas (páginas 126 y 127), unas letras que, dirigidas por ese cronista a Lola La Grande, por entonces esposa del Alfredo Leal que se acababa de consagrar con Tejón, de Mariano Ramírez, alternando esa tarde con Juan Silveti hijo y Paco Camino, que con Chatito logró también "iun faenón, lo que se dice 
un faenón! El toro, como hipnotizado, iba tras la muleta como si no supiera que embestía, así como el agua no tiene sed y el sol no sabe que alumbra", retrotraen a nuestra imaginación toda una época de la vida nacional. ${ }^{3}$

Yo tenía por ese entonces diez años, y ese día recorté del periódico la reseña del festejo, cuyos tres estupendos primeros párrafos espero se me perdone copiar aquí: "En El Toreo de Cuatro Caminos, el domingo 21 de enero de 1962. Lola siempre admirada: Parece que fue ayer, cuando en la última feria de San Marcos, parecías una estampa arrancada de la Suave Patria de López Velarde, entre gritos y risas de muchachas y pájaros de oficio carpintero. Allí estabas, plantada en medio del palenque, iengallada con los gallos!, como las cantadoras mexicanas que en las ferias -según el mismo poema de Ramón- van con el bravío pecho empitonado de la camisa. Porque así te admiramos -frescura de rebozo y de tinaja- como pintaba el dicho poeta zacatecano a las vendedoras de chía, a quienes quería raptarse en la Cuaresma opaca, sobre un garañón y con matraca, y entre los tiros de la policía. Hoy, en las angustiosas horas de la tarde, no has podido desbordar tu alegría ferial. iToreaba tu torero y has de haber pasado las horas de rodillas ante el Crucifijo de piedra, que también se puso a llorar. Porque yo he visto muchas mujeres enamoradas de su marido, pero, como tú, ninguna. Si el Cucurrucucú paloma
Para documentar la acuciosa investigación llevada a cabo por el autor al componer sus páginas, baste decir que son cincuenta los libros que anota en la bibliografía final. Y para evidenciar el buen gusto y el calor y color de redacción con que cumple su cometido vayan estos dos ejemplos: Uno, cuando se refiere a la decidida voluntad de Antonio Velázquez para seguir adelante en su camino, empedrado de sinsabores, obstáculos y heridas por asta de res: "no se le sale el valor por los agujeros de las cornadas, mas bien hacen el efecto del mazo sobre el hierro candente, a cada golpe se va templando... templando... templando..." (p. 28)

Y otro, al comentar la postrera tarde torera de quien de entre todos los diestros escogidos se nota que es el de su más personal preferencia, el

pudiera convertirse en oración, estoy seguro que lo habrías musitado como plegaria, para que la Virgen te devolviera sano y salvo a tu hombre, que estaba jugándose la vida ante los cuernos de los toros..." Tras releer esos renglones, de verdad que no puede uno menos que volverse a convencer de que así es cómo debe escribirse de toros, con esa emoción, ese bien decir, esa cultura y esa intuición de lo más profundo de la tauromaquia. 
aguascalentense por decisión propia. Rafaelillo, ídolo entre los ídolos de esta tierra provinciana en la que no nació pero en la que un día quiso quedarse para siempre:

El hambre de miedo y la sed de toros negros la saciará por última vez en la plaza de San Marcos, matando en solitario seis toros de La Punta. De todas partes del planeta de los toros se desplazaron aficionados para despedirlo. Don Rodolfo Gaona y La Diosa Rubia, Conchita Cintrón, estuvieron en los tendidos en este momento crucial de su vida y sus hijos Rafael y Nicolás le desprendieron el añadido que mostró a la concurrencia en señal de despedida, una despedida soñada por cualquiera que se diga torero. (p. 44)

Porque esa es otra de las características que confieren mayor expresividad a las cuartillas de Xavier González: un decidido localismo, la adopción del punto de vista de quien se acerca a la historia taurina desde la barrera de su plaza de San Marcos, todavía en funciones plenas y sin competidora en la ciudad "llamada la Sevilla de América” (p. 105) durante todo el tiempo que trata.

En plan detallista, podrían hacerse algunas acotaciones a los diez capítulos de Tocados por los duendes, como los de que la situación geográfica precisa del Líbano, tierra de origen de la madre de Alfredo Leal, es en el Cercano Oriente, en la costa del Mediterráneo, al norte de Israel y al sur de Siria, o la de que, para completar la pintura de ese periodo taurino al que se refiere habría que recordar cómo, por entonces, todavía participaron con importancia ciertos matadores provenientes de años anteriores, como Luis Procuna, Fermín Rivera o el trianero aguascalentense Calesero, e incluso Carlos Arruza, que hasta poco antes de fallecer trágicamente en mayo de 1966 seguía actuando con éxito, aunque ya nada más en plan de rejoneador que luego se bajaba a dar muletazos y a estoquear a pie. Y que asimismo luego ocupara sitio relevante algún otro torero que los diez escogidos, tal Jaime Rangel o Raúl García. Y que tampoco puede dejarse fuera del objetivo de la cámara de retratar a la época torera de referencia no sólo la importante participación en ella de los españoles Dominguín, Jumillano y Antonio Ordóñez, primero, y luego Paco Camino y Diego Puerta, sino también la del venezolano César Girón y, sobre todo, el Lobo portugués Manolo dos Santos. Por lo demás, no sobraría 
especificar que de los once rabos cortados en la México por Rafael Rodríguez, "situación que hoy en día todavía no es igualada por torero alguno" (p. 42), seis los obtuvo siendo novillero y sólo seis después de la alternativa. Pero esto es en verdad hilar demasiado delgado y tomar el rábano por las hojas.

Resumiendo, concluiré en que no se trata únicamente de que la lectura de este trabajo resulte imprescindible para los amantes de la fiesta de toros deseosos de reasumir un periodo ineludible dentro del contexto de una historia taurina mexicana completa, para los convencidos de la importancia de la historiografía de las diversiones en el cabal conocimiento de una sociedad cualquiera y para los aguascalentenses interesados en conseguir una adecuada imagen de su pasado regional, sino que con ella habremos también de deleitarnos con un estupendo decir y con una visión general de la historia que parte del enunciado con el que inicia González Fisher el "Paseíllo" de su texto": No todo tiempo pasado fue mejor, eso es evidente, pero también es evidente el hecho de que el presente se construye sobre el pasado y de la magnitud de ese pasado, dependerá la magnificencia de este presente. (p. 13)

Me doy por aludido con la dedicatoria que puso Xavier en mi ejemplar de Tocados...: "Espero que este libro llene tus expectativas como bibliófilo y como aficionado a los toros". Pero debo advertirle que no fue así, que soy insaciable en esas dos características de mi personalidad, y que por ello espero seguir recibiendo, en los próximos tiempos, de él y de los demás compañeros de la peña, nuevos frutos de sus ingenios, así de inteligentes, comprometidos y sentidos en su acercamiento a la historia taurina. 
